compared with $81.3 \%$ hours (IQR 38.5 to 181.3 ) in the control group (Figure 1), a reduction of 58\% (95\% CI 35\% to $73 \%$ ) $(\mathrm{p}=<0.0001)$. We found no other statistically significant differences between the two groups to term corrected age.

Conclusions Cerebral oxygenation was stabilised using a treatment guideline in combination with cerebral NIRS monitoring in extremely preterm infants.

\section{0-222 EVALUATION OF THE INFLUENCE OF BIFIDOBAKTERIUM LACTIS 2011 AND HINDIBA INULIN ON FEEDING INTOLERANCE AND NECROTISING ENTEROCOLITIS IN PREMATURE BABIES}

C El, M Satar, H Yildizdas, F Özlü, HS Asker. Pediatrics, Cukurova University School of Medicine, Adana, Turkey

\subsection{6/archdischild-2014-307384.292}

Aim To evaluate the influence of bifidobakterium lactis 2011 and hindiba inulin on feeding intolerance and necrotising enterocolitis in premature babies

Material and method 89 premature babies with the diagnosis of feeding intolerance were enrolled in the study. Premature babies were divided into two groups; Study group (group 1) had Bifidobakterium Lactis $\left(5 \times 10^{9} \mathrm{CFU}\right)+$ Hindiba Inulin $(900 \mathrm{mg})$ (Maflor $^{\mathrm{R}}$ ) liquefied with $10 \mathrm{ml}$ sterile water with the dosage of 3 $\times 1 \mathrm{ml}$ peroral while control group (group 2) did not have any medication for feeding intolerance.

Results Gender and gestational weeks of the groups were not significantly different. B. Lactis ve Hindiba Inulin was started at mean 9.9 days and continued for mean 11.1 days. Time of starting oral feeding and time of full enteral feeding were longer in study group and this was statistically significant. ( $p<0,05)$. Although NEC was not significantly different between groups ( $p$ $>0,05)$, babies in the study group diagnosed as in Grade 1 and did not progress, one third of the diagnosed babies in the control group progressed to Grade 2. When the groups were compared according to weight gain, study group gained more weights and it was statistically significant. $(\mathrm{p}<0,05)$.

Conclusion Probiotics and prebiotics may have positive effect due to higher weight gain and not advancing in NEC in study group having B. Lactis and Hindiba Inulin.

\section{0-223 THE VICI-TRIAL: AN INTERNATIONAL MULTICENTER RANDOMISED CLINICAL TRIAL COMPARING HFO AND CMV AS INITIAL VENTILATION STRATEGY IN CONGENITAL DIAPHRAGMATIC HERNIA}

${ }^{1} \mathrm{~K}$ Snoek, ${ }^{2}$ Capolupo, ${ }^{3} \mathrm{~T}$ Schaible, ${ }^{4} \mathrm{~A}$ van Heijst, ${ }^{5} \mathrm{~A}$ Greenough, ${ }^{6} \mathrm{M}$ Gorett Silva, ${ }^{7} \mathrm{~J}$ Saldanha, ${ }^{8} \mathrm{~A}$ Debeer, ${ }^{9} \mathrm{C}$ Pinto, ${ }^{1} \mathrm{D}$ Tibboel, ${ }^{10} \mathrm{I}$ Reiss. ${ }^{1}$ Intensive Care and Department of Pediatric Surgery, Erasmus MC- Sophia Children's Hospital, Rotterdam, Netherlands; ${ }^{2}$ Department of Medical and Surgical Neonatology, Bambino Gesu Children's Hospital, Rome, Italy; ${ }^{3}$ Department of Pediatrics, Universitätsmedizin Mannheim, Mannheim, Germany: ${ }^{4}$ Department of Pediatrics Division of Neonatology, Radboud University Medical Centre, Nijmegen, Netherlands; ${ }^{5}$ Division of Asthma Allergy and Lung Biology, King's College London, London, UK; ${ }^{6}$ Department of Pediatrics Division of Neonatology, Hospital San Joao, Porto, Portugal; ' Department of Pediatrics Division of Neonatology, Hospital de Santa Maria, Lisboa, Portugal; ${ }^{8}$ Neonatal Intensive Care Unit, University Hospital Leuven, Leuven, Belgium; ${ }^{9}$ Department of Paediatric Intensive Care Unit, Hospital de Pediatrico, Coimbra, Portugal; ${ }^{10}$ Department of Neonatology, Erasmus MCSophia Children's Hospital, Rotterdam, Netherlands

10.1136/archdischild-2014-307384.293

Background Congenital diaphragmatic hernia (CDH) is a lifethreatening anomaly with significant mortality and morbidity. The

\begin{tabular}{|c|c|c|c|}
\hline \multicolumn{4}{|l|}{ Variables: corrected for centre } \\
\hline (results are presented as $\mathrm{n}(\%)$ or median (IQR) & HFO $(n=80)$ & CMV $(n=91)$ & $\mathrm{p}$-value \\
\hline Length of ventilation (days) & $13(8-23)$ & $10(6-18)$ & 0.03 \\
\hline \multicolumn{4}{|l|}{ Severity CLD } \\
\hline No CLD & $37(46.3 \%)$ & $50(54.9 \%)$ & \\
\hline Mild CLD & $7(8.8 \%)$ & $13(14.3 \%)$ & \\
\hline Moderate CLD & $2(2.5 \%)$ & $1(1.1 \%)$ & \\
\hline Severe CLD & $9(11.3 \%)$ & $6(6.6 \%)$ & \\
\hline Died & $25(31.3 \%)$ & $21(23.1 \%)$ & 0.13 \\
\hline ECMO (in ECMO centres only) & $24(51.1 \%)$ & $16(26.2 \%)$ & 0.007 \\
\hline Inhaled nitric oxide & $45(56.3 \%)$ & $39(42.9 \%)$ & 0.045 \\
\hline Sildenafil & $25(31.3 \%)$ & $11(12.1 \%)$ & 0.004 \\
\hline Inotropics & $73(91.3 \%)$ & $73(80.2 \%)$ & 0.08 \\
\hline \multicolumn{4}{|l|}{ Duration inotropics (days) } \\
\hline (in survivors only) & $8(4.25-19)$ & $6(3.25-11.75)$ & 0.02 \\
\hline
\end{tabular}

lungs have a high susceptibility for oxygen and ventilation damage resulting in a high incidence of chronic lung disease (CLD).

Aim To establish the optimal initial ventilation strategy in $\mathrm{CDH}$. Methods In a prospective, randomised international multicenter trial initiated by the CDH Euroconsortium (VICI-trial, NTR 1310), prenatally diagnosed $\mathrm{CDH}$ neonates born between November 2008 and December 2013, were randomised for either conventional mechanical ventilation (CMV) or high-frequency oscillation ventilation (HFO) as initial ventilation mode. Primary outcome measure was death or CLD (Jobe and Bancalari, 2001) at day 28 analysed by multiple logistic regression analysis corrected for centre, lung-to-head ratio, liver position and side of defect. Secondary outcome was corrected for centre. Results Of the 171 included patients, 91 (53.2\%) initially received CMV (median gestational age 38.1 weeks) and 80 (46.8\%) HFO (median gestational age 38.0 weeks). In total, 21 (23.1\%) patients ventilated by CMV died and 25 (31.3\%) in HFO. Of the survivors, 21 (23.1\%) had CLD in CMV and 18 $(22.5 \%)$ in HFO. Primary outcome measure showed that in CMV 41 (45.1\%) died or had CLD at day 28 and in HFO 43 (53.8\%), OR $0.6,95 \%$ CI [0.12-2.54]. Results of secondary outcome are shown in Table 1.

Conclusions Although the primary outcome was statistically not significant, CDH patients initially ventilated by CMV were ventilated less days, received inotropics less days, and received less often nitric oxide, sildenafil and ECMO compared to HFO.

\section{0-224 TOLL-LIKE RECEPTORS GENOTYPE POLYMORPHISM IN EGYPTIAN CHILDREN WITH CHRONIC VIRAL HEPATITIS C}

'OE Soliman, ${ }^{1}$ AA Shaltout, ${ }^{1}$ BM Hasaneen, ${ }^{1}$ AE Mosaad, ${ }^{2} Y M$ Mosaad. ${ }^{1}$ Pediatrics, Mansoura University Children's Hospital, Mansoura, Egypt; ${ }^{2}$ Clinical Pathology, Faculty of Medicine Mansoura University, Mansoura, Egypt

\subsection{6/archdischild-2014-307384.294}

Background Toll-like receptors (TLRs) are important molecules for both innate and adaptive immune responses. The prevalence of TLRs polymorphism varies in different populations and controversial results were reported in HCV patients. We aimed to assess the frequency of TLR2 Arg753Gln, TLR4 Asp294Gly and TLR4 Thr399Ile polymorphisms among Egyptian children with chronic HCV and to study their relation to clinical data.

Methods An observational case control study was conducted in Mansoura University Children's Hospital, Egypt and included 
100 Chronic HCV patients (63\% males) with mean age of $13 \pm$ 2.8 years in addition to 100 healthy matched controls. Diagnosis of patients relied upon persistently positive HCV PCR for at least 6 months. Eighty two patients received combined pegylated interferon $\alpha 2 \mathrm{~b} 60 \mathrm{mcg} / \mathrm{m}^{2} / \mathrm{w}$ and ribavirin $15 \mathrm{mg} / \mathrm{kg} / \mathrm{d}$. Treatment was continued for 48 weeks for responders (49 patients). All subjects were exposed to history, examination, liver functions, viral markers, HCV PCR and abdominal ultrasound. Liver biopsy was done only for patients. Gene polymorphisms were assessed by restriction fragment length polymorphism.

Results Neither patients nor controls had TLR2 Arg753Gln or TLR4 Asp299Gly polymorphisms. Only 3 patients (3\%) were heterozygous for TLR4 Thr399lle polymorphism without significant difference between patients and controls $(p=0.24)$. No significant correlation was observed between TLR4 Thr399Ile polymorphism and viral load, histologic activity, grade of fibrosis or treatment response ( $\mathrm{p}=0.96,0.21,0.46,0.49$ respectively). Conclusion TLR2 Arg753Gln, TLR4 Asp294Gly and TLR4 Thr399Ile polymorphisms seem to be absent or rare and probably have no role in HCV among Egyptian population.

\section{0-225 LNCRNAS ARE PREFERENTIALLY LOCATED NEAR TRANSCRIPTION FACTORS AND REGULATE EARLY ENDODERM AND LUNG DEVELOPMENT}

${ }^{1} \mathrm{D}$ Swarr, ${ }^{2} \mathrm{M}$ Herriges, ${ }^{3} \mathrm{M}$ Morley, ${ }^{3} \mathrm{M}$ Lu, ${ }^{3} \mathrm{~K}$ Stewart, $2,3,4,5 \mathrm{EE}$ Morrisey . ${ }^{1}$ Div. of Neonatology and Human Genetics, The Children's Hospital of Philadelphia; ' 2 Department of Cell and Developmental Biology; ${ }^{3}$ Department of Medicine; ${ }^{4}$ Institute for Regenerative Medicine; ${ }^{5}$ The Cardiovascular Research Institute, U. of Pennsylvania, Philadelphia, PA

10.1136/archdischild-2014-307384.295

Although long non-coding RNAs (lncRNAs) have been demonstrated to regulate fundamental biologic processes, such as cell proliferation and maintenance of the pluripotent state, their patterns of expression and role during mammalian development remains poorly defined. Using RNA-Seq with a conservative pipeline, we have identified 363 lncRNAs in the lung and

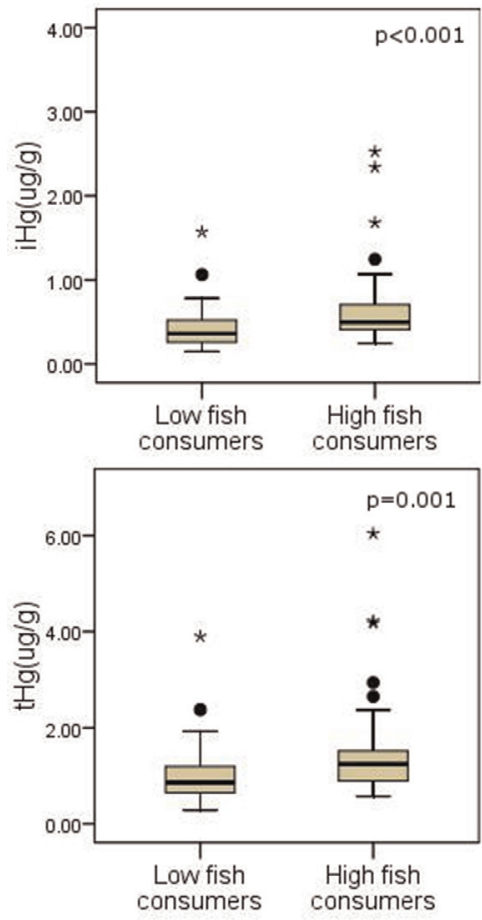

foregut endoderm. These lncRNAs were 3 -fold more likely to be located within $20 \mathrm{~kb}$ of a known transcription factor compared to protein-coding genes. Three lncRNAs were selected for indepth analysis: two lncRNAs adjacent to the critical transcription factors Foxa2 (LncFoxa2) and Nkx2.1 (Nkx2.1-Associated NonCodIng RNA, Nanci), and a novel lncRNA (LL34) with markedly increased expression in embryonic lung. In situ hybridization revealed distinct patterns of expression in the lung for each of these transcripts, with nearly identical patterns of expression between Foxa2 and Nkx2.1 with their neighbouring lncRNAs. Lentiviral shRNA-mediated knockdown of LL34 revealed alterations in the expression of genes involved in early patterning of the foregut and lung, including genes involved in retinoic acid (RA) synthesis, and downstream targets of RA signalling including Foxa1, Gata6, Bmp2, Fgfr2, Fgfr3, and Tgfb3. Most recently, CRISPR-Cas9 technology has been used to generate stable hepatocyte knockout lines of LncFoxa2, which demonstrate that LncFoxa2 may function to regulate endoderm development by both regulation of its neighbouring transcription factor, and also through mechanisms independent of Foxa2. Taken together, these data suggest that lncRNAs play critical roles in the patterning, growth, and differentiation of the foregut and lung.

Funding for this research was provided by NIH 5 U01 HL110942 02 and NIH 5 T32GM008638 17.

\section{Adolescent Health}

\section{PS-001 FISH CONSUMPTION PATTERN AND ITS ASSOCIATION WITH HAIR MERCURY LEVELS IN HONG KONG PRESCHOOL CHILDREN}

${ }^{1}$ PHY Chan, ${ }^{1} \mathrm{HS}$ Lam, ${ }^{1} \mathrm{CLS}$ Chau, ${ }^{2} \mathrm{RCK}$ Cheung, ${ }^{2} \mathrm{MHM}$ Chan, ${ }^{1} \mathrm{AM}$ Li. ${ }^{1}$ Department of Paediatrics, The Chinese University of Hong Kong, Hong Kong, China; ${ }^{2}$ Department of Chemical Pathology, The Chinese University of Hong Kong, Hong Kong, China

\subsection{6/archdischild-2014-307384.296}

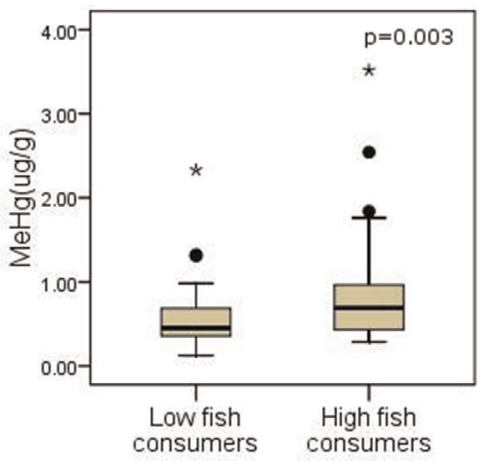

Abstract PS-001 Figure 1 Box plot graphs for low and high fish consumers of their hair iHg, MeHg and tHg MeHg, tHg levels 